\title{
Effects of olfactory training: a meta-analysis*
}

\author{
Agnieszka Sorokowska ${ }^{1,2 \#}$, Edda Drechsler ${ }^{1 \#,}$, Maciej Karwowski ${ }^{3}$, \\ Thomas Hummel ${ }^{1}$ \\ Smell and Taste Clinic, Department of Otorhinolaryngology, TU Dresden, Dresden, Germany \\ ${ }^{2}$ Institute of Psychology, University of Wroclaw, Wroclaw, Poland \\ The Maria Grzegorzewska University, Warsaw, Poland
}

Rhinology 55: 17-26, 2017

https://doi.org/10.4193/Rhino16.195

*Received for publication:

June 18, 2016

Accepted: September 19, 2016

\# shared first authorship

\begin{abstract}
The neural plasticity of the olfactory system o ers possibilities of treatment in terms of stimulation of the sense of smell, and different studies have suggested e ectiveness of smell training, i.e., daily exposition to certain odors. To obtain reliable and precise estimates of overall treatment bene $t$ on the olfactory function, we meta-analyzed the e ects of smell training reported in 13 previous studies. We analyzed the smell training e ectiveness across three di erent olfactory abilities - smell identi cation, discrimination and threshold for odor detection. We found a signi cant, positive e ect of olfactory training for all olfactory abilities, with large e ects of training on identi cation, discrimination and TDI-score and small-to-moderate e ect in the case of threshold for odor detection. Interestingly, the pattern of results di ered across Sni n'Sticks subtests depending on the origin of participants' smell disorder, and the smell training duration in uenced its e ectiveness in the case of identi cation and the TDI score. Although the exact mechanism of olfactory recovery following the smell training still requires further investigation, our meta-analysis sho- wed that such training should be considered an addition or alternative to existing smell treatment methods.
\end{abstract}

Key words: therapy, smell, nose, regeneration, anosmia

\section{Introduction}

Currently there is no generally approved way to treat olfactory impairment resulting from causes other than sinunasal diseases. However, the neural plasticity of the olfactory system offers possibilities of treatment in terms of stimulation of the sense of smell. Regenerative capacities of the olfactory pathway include mechanisms ranging from changes in membrane excitability to changes in synaptic efficacy to neurogenesis and apoptosis (1). As odors can influence this regenerative capacity (2-4), "smell training" has been a basis of research conducted in various smell and taste clinics. The method is very simple - people are asked to sniff four different odors, usually one odor of the categories: flowery, fruity, spicy and resinous. Such training is performed twice a day for a certain time period (usually between 4 to 6 months). The "olfactory training" may result in the improvement of verbal functions or the increased expression of olfactory receptor neurons / an increased growth of olfactory receptor neurons ${ }^{(3,4)}$.

Different studies have suggested that the smell training is promising ${ }^{(5-21)}$. Olfactory improvement through olfactory training was investigated in patients with smell dysfunction ${ }^{(5-13,19)}$, as well as in older ${ }^{(17,20)}$, and younger healthy people ${ }^{(14,21)}$. However, given that not under all circumstances the training proved to lead to significant smell improvement (e.g. in older subjects) (17), we decided to examine the previous findings in a metaanalysis. As we aimed to obtain reliable and precise estimates of overall treatment benefit on the olfactory function, we explored the effects of smell training on different olfactory modalities measured by the Sniffin' Sticks Test ${ }^{(22,23)}$, i.e., threshold for odor detection, discrimination, identification, and the scores of the full test (threshold-discrimination-identification; TDI score).

\section{Materials and methods}

\section{Search strategies}

We conducted an extensive literature search to identify empirical studies that involved an evaluation of aspects of smell training. First, we reviewed articles and research papers in English and German. We searched EBSCO, PsycExtra, Academic Search Complete, Psyclnfo, PsycArticles, and ERIC databases and used the resources of JSTOR, Science Direct, SAGE Journals, Taylor \& 
Francis, and ProQuest using the following keywords: smell training and olfactory training. In the next step, we analyzed book publications using three electronic libraries: Wiley Online Library and Questia, as well as Google Books.

\section{Inclusion criteria}

Our initial search yielded a total of twenty potential reports. As we wanted to analyze the effect of smell training on different olfactory abilities, we only considered studies investigating the effects of olfactory training that involved Sniffin' Sticks Test ${ }^{(22,24)}$. A total of seven studies did not meet this first selection criterion and were eliminated from the analysis (Table 1), and thus a total of 13 reports were included in the analysis.

We analyzed scores in each Sniffin' Sticks subtest separately. The number of available studies (and consequently, participants) differed across subtests (Table 2 and Table 3). There were 13 studies on a total sample of $n=1005$ participants in the case of identification, 10 studies $(n=788)$ in the case of discrimination, 12 studies $(n=951)$ in the case of threshold and 11 studies ( $=879$ ) in the case of the full TDI score. Participants had a mean age of $\mathrm{M}=54.0$ years $(\mathrm{SD}=16.0$ ). The studies were conducted between 2009 and 2016, in various countries. Table 2 provides a detailed overview of the studies included in the meta-analysis.

\section{Coding procedures}

The first two authors independently coded each article for relevant information, including: sample size, sample selection, main statistics necessary to the computation of effect size, and information necessary for the moderator analyses (i.e., duration of the training, participants' age, participants' characteristics:
Parkinson disease, patients versus non-patients, patients with postinfectious olfactory loss, patients with postinfectious and posttraumatic olfactory loss and older healthy people). Next, we reviewed the coded data and articles, discussed and resolved any discrepancies to help eliminate errors in coding.

\section{Moderators}

For each study included in our meta-analysis, we coded for the key moderators of interest. Specifically we included the duration of the training (continuous variable) as well as four dichotomous moderators, based on characteristics of smell training participants: 1) participants with Parkinson disease $(k=2)$ versus participants without Parkinson disease; 2) participants with olfactory diseases (all types) $(\mathrm{k}=8)$ versus participants without olfactory diseases; 3 ) patients with postinfectious olfactory loss ( $k=5$ ) versus other participants; 4) patients with postinfectious and posttraumatic olfactory loss $(k=6)$ versus other participants; and finally 5) older (healthy) people $(k=2)$ versus other participants.

\section{Statistical methods}

We computed individual effect size for each study using the values of means and pooled standard deviations and standardized them to obtain Hedges $g^{(25,26)}$. In the case of multiple effects within a study, effects were averaged. To analyze the main effects, we used random effects meta-analysis using the metafor package in $\mathrm{R}^{(27)}$ and macros for SPSS ${ }^{(28)}$. We used Cohen's ${ }^{(25)}$ guidelines to interpret the effect size obtained, hence $g=0.20$ is interpreted as small effect, $\mathrm{g}=0.50$ as moderate effect and $\mathrm{g}=$ 0.80 as a large effect.

Table 1. Studies excluded from the current meta-analysis.

\begin{tabular}{|c|c|c|}
\hline Authors & Title & Main finding \\
\hline Livermore \& Hummel, $2004{ }^{(34)}$ & $\begin{array}{l}\text { The influence of training on chemosensory event-rela- } \\
\text { ted potentials and interactions between the olfactory } \\
\text { and trigeminal systems }\end{array}$ & $\begin{array}{l}\text { Strong and specific training effects in intensity ratings } \\
\text { for participants trained with the test odor, but not for } \\
\text { those trained with a different odor }\end{array}$ \\
\hline Mariño-Sánchez et al., $2010^{(35)}$ & $\begin{array}{l}\text { Smell training increases cognitive smell skills of wine } \\
\text { tasters compared to the general healthy population. } \\
\text { The WINECAT Study }\end{array}$ & $\begin{array}{l}\text { Wine tasters performed significantly better on identi- } \\
\text { fication and forced choice than healthy controls. }\end{array}$ \\
\hline Tempere et al., $2012^{(36)}$ & $\begin{array}{l}\text { Explicit sensory training improves the olfactory sensi- } \\
\text { tivity of wine experts }\end{array}$ & $\begin{array}{l}\text { Learning was not generalized but was odorant } \\
\text { specific }\end{array}$ \\
\hline Borromeo et al., $2013^{(37)}$ & $\begin{array}{l}\text { Objective assessment of a new olfactory rehabilitation } \\
\text { approach in adults with olfactory impairments using } \\
\text { functional magnetic resonance (fMRI) }\end{array}$ & Increased activation in orbitofrontal and insular cortex \\
\hline Delon-Martin et al., 2013 & $\begin{array}{l}\text { Perfumers' expertise induces structural reorganization } \\
\text { in olfactory brain regions }\end{array}$ & $\begin{array}{l}\text { Increase in gray-matter volume in the bilateral gyrus } \\
\text { rectus/medial orbital gyrus }\end{array}$ \\
\hline Negoias et al., $2013^{(38)}$ & Localization of odors can be learned & $\begin{array}{l}\text { Subjects performing lateralization training improve in } \\
\text { their ability to lateralize olfactory stimuli }\end{array}$ \\
\hline Royet et al., $2013^{(39)}$ & The impact of expertise in olfaction & $\begin{array}{l}\text { Review describes changes on behavioral, functional, } \\
\text { and structural levels in relation to odor expertise }\end{array}$ \\
\hline
\end{tabular}


MII

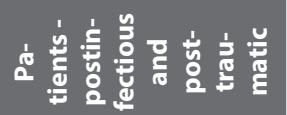

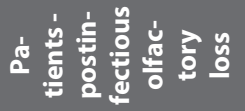
da

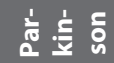

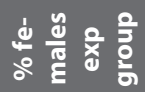

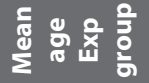

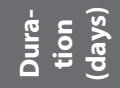
$\$$

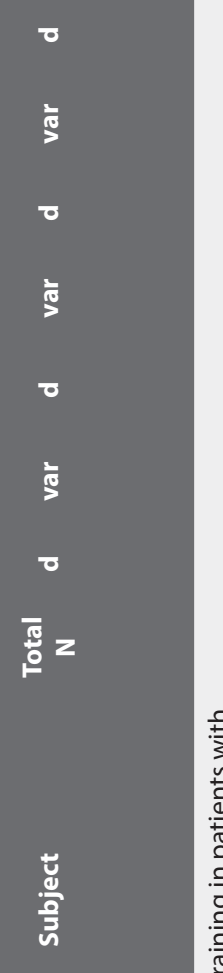

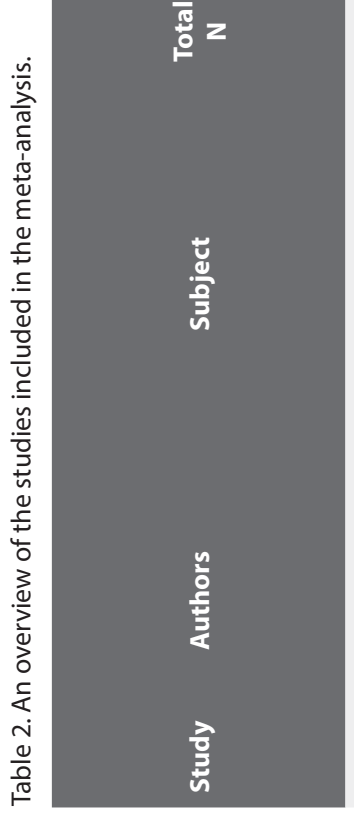

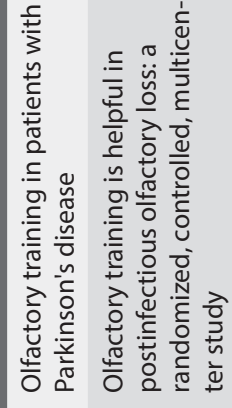

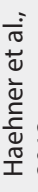
g ल.

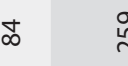
$\stackrel{8}{\circ}$ $\pm$ :) $\stackrel{\infty}{\circ}$ : ₹.

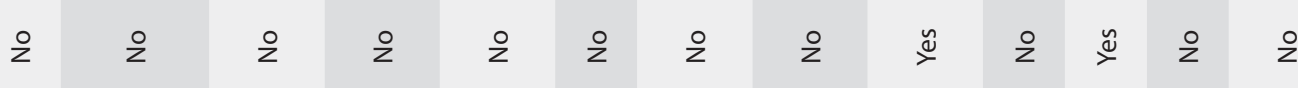

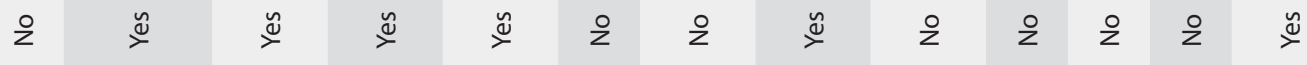

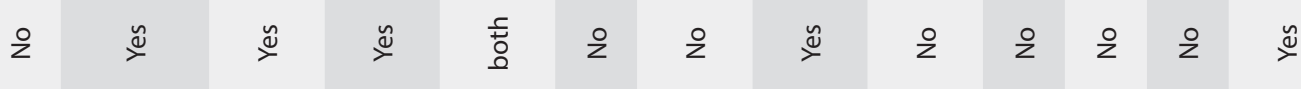

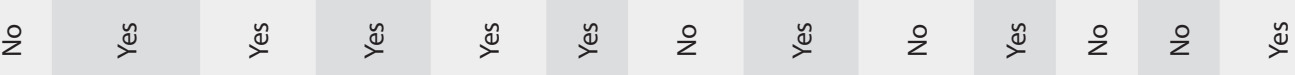
$\stackrel{0}{2} \stackrel{2}{z}$

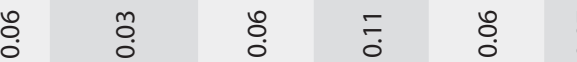

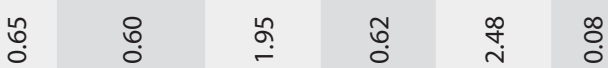
$\therefore \quad \stackrel{\circ}{\square} \stackrel{\circ}{\square}$

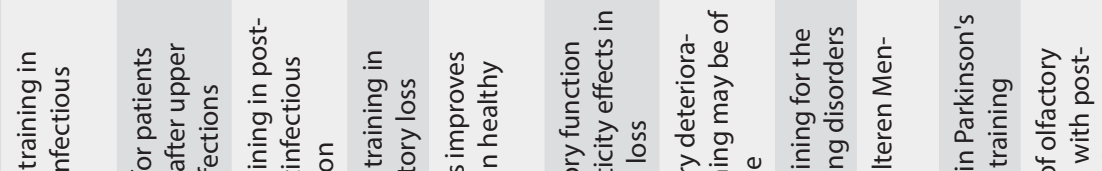

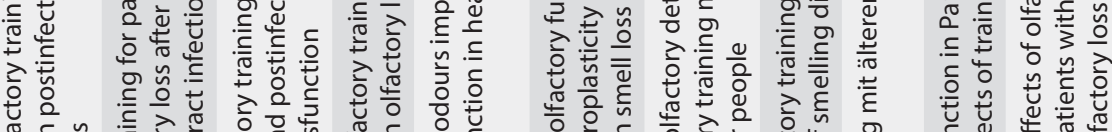

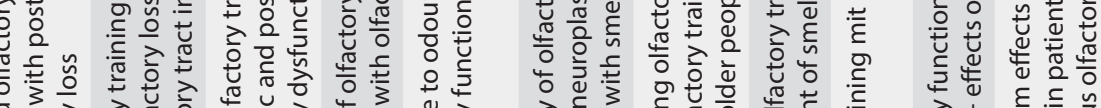

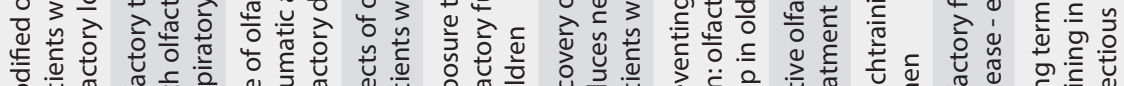

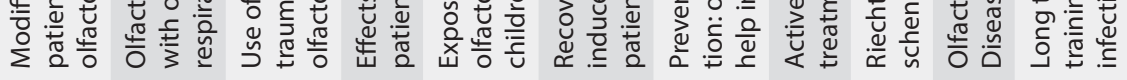

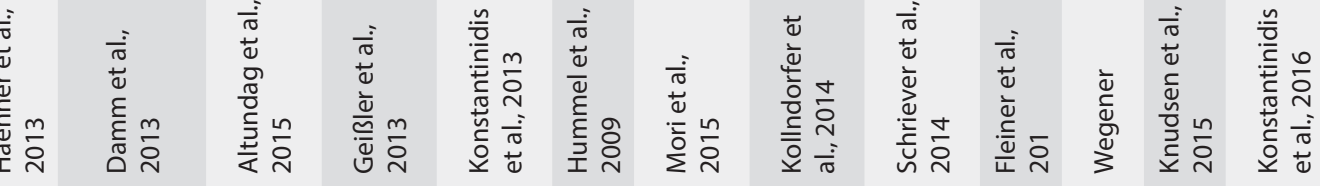


Table 3. Overall effect size obtained using random effects meta-analysis.

\begin{tabular}{|c|c|c|c|c|c|c|}
\hline & k & $\mathbf{N}$ & g & $95 \% \mathrm{Cl}$ & $\mathbf{p}$ & $\mathbf{Q}$ \\
\hline Identification & 13 & 1005 & 0.833 & $0.264,1.402$ & .004 & $200.66^{* * *}$ \\
\hline Discrimination & 10 & 788 & 0.890 & $0.498,1.298$ & $<.001$ & $57.06^{* * *}$ \\
\hline Threshold & 12 & 951 & 0.336 & $0.103,0.569$ & .005 & $32.37^{* * *}$ \\
\hline TDI & 11 & 879 & 1.10 & $0.459,1.734$ & $<.001$ & 172.73 \\
\hline
\end{tabular}

$\mathrm{k}=$ total number of studies; $\mathrm{N}=$ number of participants, $\mathrm{g}=$ Hedges' $\mathrm{g} ; 95 \% \mathrm{Cl}=95 \%$ confidence intervals; $\mathrm{Q}=$ heterogeneity statistics (the number of degrees of freedom is $\mathrm{k}-1) .{ }^{* * *} \mathrm{p}<.001$

Table 4. Meta-analysis analog of ANOVA: summary of moderators (identification).

\begin{tabular}{|c|c|c|c|c|c|}
\hline & $\mathbf{k}$ & g & $95 \% \mathrm{Cl}$ & $\mathbf{p}$ & Qwithin \\
\hline \multicolumn{6}{|c|}{ Parkinson Disease } \\
\hline No & 11 & 0.92 & $0.34,1.50$ & .002 & 12.75 (ns) \\
\hline Yes & 2 & 0.39 & $-0.94,1.71$ & .57 & 0.00 (ns) \\
\hline \multicolumn{6}{|c|}{ Patients with olfactory diseases (all types) } \\
\hline No & 5 & 0.22 & $-0.50,0.93$ & .55 & 0.20 (ns) \\
\hline Yes & 8 & 1.26 & $0.68,1.85$ & $<.001$ & 12.93 (ns) \\
\hline \multicolumn{6}{|c|}{ Patients (Postinfectious olfactory loss) ${ }^{\mathrm{a}}$} \\
\hline No & 7 & 0.29 & $-0.27,0.85$ & .31 & 0.43 (ns) \\
\hline Yes & 5 & 1.42 & $0.73,2.11$ & $<.001$ & $11.86^{*}$ \\
\hline \multicolumn{6}{|c|}{ Patients (Postinfectious and posttraumatic olfactory loss) } \\
\hline No & 7 & 0.29 & $-0.27,0.85$ & .31 & 0.43 (ns) \\
\hline Yes & 6 & 1.54 & $0.93,2.15$ & $<.001$ & $13.05^{*}$ \\
\hline \multicolumn{6}{|c|}{ Older people (healthy) } \\
\hline No & 11 & 0.96 & $0.40,1.53$ & $<.001$ & 12.79 (ns) \\
\hline Yes & 2 & 0.18 & $-1.09,1.46$ & .78 & 0.00 (ns) \\
\hline
\end{tabular}

${ }^{a}=$ one study ${ }^{(19)}$ covering both: patients with postinfectious and posttraumatic olfactory loss was excluded from this analysis. The number of degrees of freedom for Qwithin is the number of studies minus 1. ns = non-significant; ${ }^{*} \mathrm{p}<.05 ;{ }^{* *} \mathrm{p}<.01 ;{ }^{* * *} \mathrm{p}<.001$.

\section{Results}

We present the results of the meta-analysis in three steps. First, we show a general estimation of the effect size obtained in the random effect meta-analysis for each of analyzed aspects, i.e., identification, discrimination, threshold, and TDI. Next, we examine whether our estimates are robust in terms of publication bias. Finally, we focus on the role of moderators.

\section{Overall effect}

Table 3 presents the overall effect of the smell training effectiveness. The obtained mean effect size was consistent with our expectations. More specifically, there was a strong, positive and statistically significant relationship in the case of three out of four analyzed criteria: identification ( $g=0.83$ ), discrimination ( $g$ $=0.89)$ and TDI-score $(g=1.10)$ and small-to-moderate effect in the case of threshold $(g=0.34)$. All effects apart from TDI were also heterogeneous (as illustrated by statistically significant values of $Q$ statistics), which supported our decision to include moderators, potentially responsible for this heterogeneity. Prior to examining the influence of moderators, however, we tested to what extent the obtained effects could be influenced by publication bias. 
Table 5. Meta-analysis analog of ANOVA: summary of moderators (discrimination).

\begin{tabular}{|c|c|c|c|c|c|}
\hline & k & $\mathbf{g}$ & $95 \% \mathrm{Cl}$ & $\mathbf{p}$ & Qwithin \\
\hline \multicolumn{6}{|c|}{ Parkinson Disease } \\
\hline No & 9 & 0.88 & $0.46,1.30$ & $<.001$ & 9.95 (ns) \\
\hline Yes & 1 & 1.08 & $-0.15,2.31$ & .08 & NA \\
\hline \multicolumn{6}{|c|}{ Patients with olfactory diseases (all types) } \\
\hline No & 2 & 1.09 & $0.24,1.95$ & .01 & 0.00 (ns) \\
\hline Yes & 8 & 0.85 & $0.40,1.29$ & $<.001$ & 9.88 (ns) \\
\hline \multicolumn{6}{|c|}{ Patients (Postinfectious olfactory loss) ${ }^{\mathrm{a}}$} \\
\hline No & 4 & 0.56 & $0.05,1.08$ & .03 & 4.66 (ns) \\
\hline Yes & 5 & 1.00 & $0.52,1.48$ & $<.001$ & 4.41 (ns) \\
\hline \multicolumn{6}{|c|}{ Patients (postinfectious and posttraumatic) $(\mathrm{Q}=2.68, \mathrm{~ns})$} \\
\hline No & 4 & 0.56 & $0.05,1.08$ & .03 & 4.66 (ns) \\
\hline Yes & 6 & 1.15 & $0.70,1.61$ & $<.001$ & 6.04 (ns) \\
\hline \multicolumn{6}{|c|}{ Older people (healthy) $(\mathrm{Q}=0.12, \mathrm{~ns})$} \\
\hline No & 9 & 0.87 & $0.45,1.30$ & $<.001$ & 9.45 (ns) \\
\hline Yes & 1 & 1.11 & $-0.10,2.30$ & .07 & NA \\
\hline
\end{tabular}

${ }^{\mathrm{a}}=$ one study ${ }^{(19)}$ covering both: patients with postinfectious and posttraumatic olfactory loss was excluded from this analysis. The number of degrees of freedom for Qwithin is the number of studies minus 1. ns = non-significant; NA = non-applicable; ${ }^{*} \mathrm{p}<.05 ;{ }^{* *} \mathrm{p}<.01 ;{ }^{* * *} \mathrm{p}<.001$

Table 6. Meta-analysis analog of ANOVA: summary of moderators (threshold).

\begin{tabular}{|c|c|c|c|c|c|}
\hline & $\mathbf{k}$ & g & $95 \% \mathrm{Cl}$ & $\mathbf{p}$ & Qwithin \\
\hline \multicolumn{6}{|c|}{ Parkinson Disease } \\
\hline No & 11 & 0.36 & $0.12,0.59$ & .004 & 12.71 (ns) \\
\hline Yes & 1 & 0.14 & $-0.64,0.91$ & .73 & NA \\
\hline \multicolumn{6}{|c|}{ Patients with olfactory diseases (all types) } \\
\hline No & 4 & 0.64 & $0.35,0.93$ & $<0.01$ & $8.69^{*}$ \\
\hline Yes & 8 & 0.15 & $-0.06,0.37$ & .17 & 5.05 (ns) \\
\hline \multicolumn{6}{|c|}{ Patients (Postinfectious olfactory loss) ${ }^{a}$} \\
\hline No & 6 & 0.43 & $0.12,0.75$ & .007 & 10.72 (ns) \\
\hline Yes & 5 & 0.32 & $-0.03,0.67$ & .07 & 1.44 (ns) \\
\hline \multicolumn{6}{|c|}{ Patients (postinfectious and posttraumatic olfactory loss) } \\
\hline No & 6 & 0.43 & $0.12,0.75$ & .007 & 10.72 (ns) \\
\hline Yes & 6 & 0.24 & $-0.07,0.54$ & .13 & 2.49 (ns) \\
\hline \multicolumn{6}{|c|}{ Older people (healthy) } \\
\hline No & 10 & 0.27 & $0.03,0.51$ & .03 & 12.64 (ns) \\
\hline Yes & 2 & 0.59 & $0.10,1.08$ & .02 & 0.56 (ns) \\
\hline
\end{tabular}

${ }^{a}=$ one study ${ }^{(19)}$ covering both: patients with postinfectious and posttraumatic olfactory loss was excluded from this analysis. The number of degrees of freedom for Qwithin is the number of studies minus 1. ns = non-significant; NA $=$ non-applicable; ${ }^{*} p<.05 ;{ }^{* *} \mathrm{p}<.01 ;{ }^{* * *} p<.001$. 

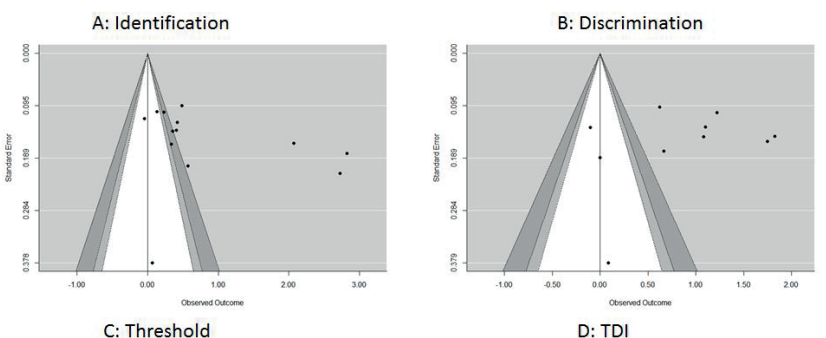

D: TDI
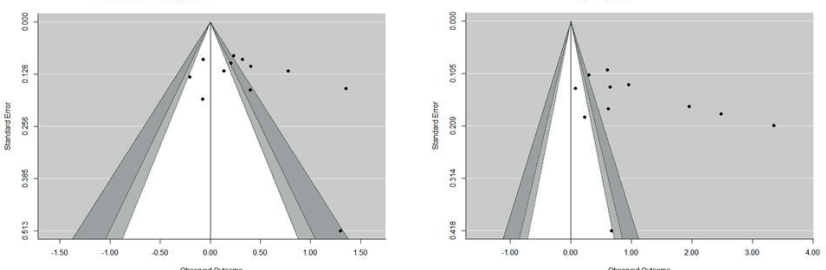

Figure 1. A funnel plot assessing the possible publication bias.

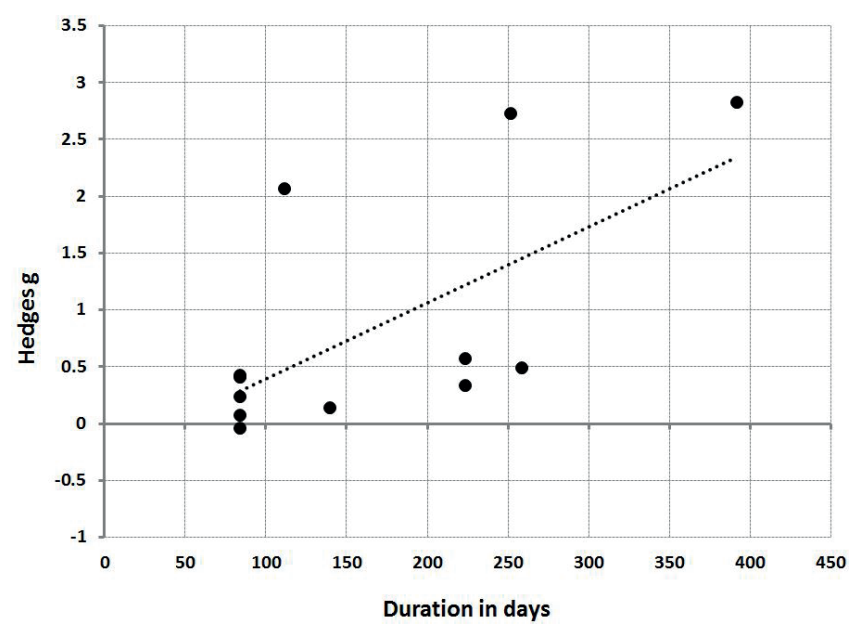

Figure 2. The relationship between training duration and the effect size observed in the case of identification.

\section{Publication bias}

To examine whether the obtained effect sizes were influenced by publication bias we used a funnel plot ${ }^{(29,30)}$ rank correlation method to estimate possible bias.

A visual inspection of the funnel plot (Figure 1, panels A-D) does not suggest asymmetry (i.e., correlations on one side of the funnel do not seem to be regularly suppressed by the effects on the other side). This pattern suggests a lack of publication bias (although such an interpretation is based more on a qualitative judgment, than strict statistical rules). In line with this pattern, Begg and Mazumdar rank correlation did not indicate a bias in case of identification (Kendall's $\mathrm{\tau}=.39, \mathrm{p}=.08$ ), discrimination (Kendall's $\tau=-.16, p=.60$ ), threshold (Kendall's $\tau=.15, p=.55$ ), nor TDI (Kendall's $\tau=.35, p=.17$ ). These findings legitimize the conclusion that publication bias did not substantively influence our estimations.

\section{Moderator analysis}

In an effort to provide a summary of estimated effects of the moderators, we conducted a meta-analysis analog of ANOVA using the estimations obtained at the study level. As the training duration formed a continuous variable (transformed into number of days) we supplemented our analyses with meta-regression. For clarity purposes, we present results of the analyses separately for each of the criteria.

\section{Identification}

Characteristics of the participants as well as the training duration clearly moderated the effect observed for identification. As presented in Table 4, the effects obtained in studies on participants with Parkinson disease did not differ significantly from other studies $(\mathrm{Q}=0.52 ; \mathrm{df}=1 ; \mathrm{p}=.47)$ : but while the effect observed in studies among Parkinson disease participants was not significant ( $\mathrm{g}=0.39,95 \% \mathrm{Cl}:-0.94-1.71, \mathrm{p}=.57$ ), the effect observed in the remaining studies was not only strong and statistically significant ( $g=0.92,95 \% \mathrm{Cl}: 0.34-1.50 ; p=.002)$, but also homogeneous $(\mathrm{Q}=12.75 ; \mathrm{df}=10, \mathrm{p}=.24)$. Apart from these differences, $95 \% \mathrm{Cl}$ intervals of both effects overlapped to a large extent, therefore they did not differ from one another.

The training effects on identification were significantly moderated by participants' olfactory disease versus no-olfactory disease status. When we aggregated patients with olfactory diseases of all types into one group $(\mathrm{k}=8)$, we observed statistically significant differences between obtained effects $(Q=4.93, \mathrm{df}=1, \mathrm{p}=$ .03). Effect estimated among people with no olfactory disease was weak and non-significant $(\mathrm{g}=0.22,95 \% \mathrm{Cl}:-0.50-0.93, \mathrm{p}=$ $.55)$, while the effect observed among patients with olfactory diseases was very strong and homogeneous $(\mathrm{g}=1.26,95 \% \mathrm{Cl}$ : 0.68-1.85; $\mathrm{p}<.001 ; \mathrm{Q}=12.93 ; \mathrm{df}=7, \mathrm{p}=.07$ ).

Similar pattern was observed when we created a more specific group of studies on patients with postinfectious olfactory loss $(\mathrm{k}$ $=5)$. Effect observed in these studies was very strong $(\mathrm{g}=1.42$; $95 \% \mathrm{Cl}: 0.73-2.11, \mathrm{p}<.001)$ and significantly stronger $(\mathrm{Q}=6.21$; $\mathrm{df}=1 ; \mathrm{p}=.01)$ than in the remaining studies $(\mathrm{g}=0.29,95 \% \mathrm{Cl}$ : $-0.27-0.85 ; p=.31)$. Effect observed among these patients was heterogeneous $(\mathrm{Q}=11.86 ; \mathrm{df}=4 ; \mathrm{p}=.02)$, which warrants future studies on possible moderators. When we analyzed the training effects among patients with postinfectious and posttraumatic olfactory loss, we observed a very strong positive effect ( $\mathrm{g}=$ 1.54; $95 \% \mathrm{Cl}: 0.93-2.15 ; \mathrm{p}<.001)$, that was also significantly heterogeneous $(\mathrm{Q}=13.05 ; \mathrm{df}=4 ; \mathrm{p}=.02)$ and stronger $(\mathrm{Q}=9.01 ; \mathrm{df}$ $=1 ; \mathrm{p}=.003)$ than effect observed in the remaining studies $(\mathrm{g}=$ $0.29,95 \% \mathrm{Cl}:-0.27-0.85 ; \mathrm{p}=.31$ ).

Although studies on healthy older people did not bring significantly different results than the remaining studies $(Q=1.21$; 
Table 7. Meta-analysis analog of ANOVA: summary of moderators (TDI).

\begin{tabular}{|c|c|c|c|c|c|}
\hline & $\mathbf{k}$ & $\mathbf{g}$ & $95 \% \mathrm{Cl}$ & $\mathbf{p}$ & Qwithin \\
\hline \multicolumn{6}{|c|}{ Parkinson Disease } \\
\hline No & 10 & 1.15 & $0.51,1.78$ & $<.001$ & 10.70 (ns) \\
\hline Yes & 1 & 0.65 & $-1.31,2.61$ & .52 & NA \\
\hline \multicolumn{6}{|c|}{ Patients with olfactory diseases (all types) } \\
\hline No & 3 & 0.63 & $-0.45,1.72$ & .25 & 0.23 (ns) \\
\hline Yes & 8 & 1.29 & $0.60,1.98$ & .0002 & 10.54 (ns) \\
\hline \multicolumn{6}{|c|}{ Patients (Postinfectious olfactory loss) ${ }^{\mathrm{a}}$} \\
\hline No & 5 & 0.45 & $-0.25,1.15$ & .21 & 0.80 (ns) \\
\hline Yes & 5 & 1.52 & $0.79,2.25$ & $<.001$ & 8.95 (ns) \\
\hline \multicolumn{6}{|c|}{ Patients (postinfectious and posttraumatic olfactory loss) } \\
\hline No & 5 & 0.45 & $-0.25,1.15$ & .21 & 0.80 (ns) \\
\hline Yes & 6 & 1.69 & $1.03,2.36$ & $<.001$ & $10.09(\mathrm{~ns})$ \\
\hline \multicolumn{6}{|c|}{ Older people (healthy) $(\mathrm{Q}=1.26, \mathrm{~ns})$} \\
\hline No & 9 & 1.21 & $0.55,1.87$ & $<.001$ & 10.51 (ns) \\
\hline Yes & 2 & 0.63 & $-0.73,1.98$ & .36 & 0.22 (ns) \\
\hline
\end{tabular}

${ }^{\mathrm{a}}=$ one study ${ }^{(19)}$ covering both: patients with postinfectious and posttraumatic olfactory loss was excluded from this analysis. The number of degrees of freedom for Qwithin is the number of studies minus 1. ns = non-significant; ${ }^{*} \mathrm{p}<.05 ;{ }^{* *} \mathrm{p}<.01 ;{ }^{* * *} \mathrm{p}<.001$

$\mathrm{df}=1 ; \mathrm{p}=.27)$, it is worth to mention, that only in studies that did not include healthy older people a significant effect was observed ( $g=0.96 ; 95 \% \mathrm{Cl}: 0.40-1.53 ; \mathrm{p}<.001$ ), while no such effect was observed among older people $(\mathrm{g}=0.18 ; 95 \% \mathrm{Cl}$ :

-1.09-1.46; $p=.78$ ).

Meta-regression with effect size regressed on a training duration demonstrated significant and strong effect of duration: $\beta=.63$, $\mathrm{p}=.006, \mathrm{R} 2=.40$. As illustrated by Figure 2 , longer training was clearly more effective.

\section{Discrimination}

None of the analyzed factors did moderate effects obtained in the case of discrimination (Table 5). The improvement of discrimination was statistically significant in studies among participants without Parkinson's disease ( $\mathrm{g}=0.88 ; 95 \% \mathrm{Cl}$ : 0.46-1.30; $\mathrm{p}<.001$ ), but also marginally significant in one study among participants with Parkinson's disease $(g=1.08 ; 95 \% \mathrm{Cl}:-0.15$ -

$2.31 ; p=.08)$. These two effects did not differ one from another, $\mathrm{Q}=0.10 ; \mathrm{df}=1 ; \mathrm{p}=.75$ ).

Similarly, smell training was equally effective $(Q=0.25 ; \mathrm{df}=1 ; \mathrm{p}$ $=.62$ ) among patients with olfactory disorders $(\mathrm{g}=0.85 ; 95 \% \mathrm{Cl}$ : $0.40-1.29 ; \mathrm{p}<.001$ ) and among people without olfactory disorders ( $g=1.09 ; 95 \% \mathrm{Cl}: 0.24-1.95 ; \mathrm{p}=.01)$. A more detailed focus on different categories of patients did not change this overall pattern: when we compared effects obtained in studies on patients with postinfectious olfactory loss with remaining studies, no differences were observed $(\mathrm{Q}=1.47 ; \mathrm{df}=1 ; \mathrm{p}=.23)$. Training among patients was highly effective $(\mathrm{g}=1.00 ; 95 \% \mathrm{Cl}$ : 0.52-1.48; $\mathrm{p}<.001)$, but the effect observed in the remaining studies was significant as well ( $\mathrm{g}=0.56 ; 95 \% \mathrm{Cl}: 0.05-1.18 ; \mathrm{p}=.03$ ). Training among postinfectious and posttraumatic patients was similarly effective as other interventions $(Q=2.68 ; \mathrm{df}=1 ; \mathrm{p}=.10)$, with strong and significant effects observed among patients ( $\mathrm{g}=$ $1.15 ; 95 \% \mathrm{Cl}: 0.70-1.61 ; \mathrm{p}<.001)$, and significant effects in the remaining studies ( $\mathrm{g}=0.56 ; 95 \% \mathrm{Cl}: 0.05-1.18 ; \mathrm{p}=.03$ ).

An individual study among older, healthy people yielded a strong, but non-significant training effect $(\mathrm{g}=1.11 ; 95 \% \mathrm{Cl}$ : -0.10-2.30; $\mathrm{p}=.07$ ), while other studies were characterized by similar effects $(\mathrm{Q}=0.12 ; \mathrm{df}=1 ; \mathrm{p}=.73)(\mathrm{g}=0.87 ; 95 \% \mathrm{Cl}$ : 0.45 $1.30 ; p<.001)$. In the case of discrimination, training duration was not related to its effectiveness, $\beta=.18, p=.56$.

\section{Threshold}

Moderator analysis in the case of threshold revealed a significant difference in the effects obtained in studies with and without patients with olfactory diseases $(Q=7.10 ; d f=1 ; p=.01$ ) (Table 6). The smell training effectiveness in the case of threshold was 


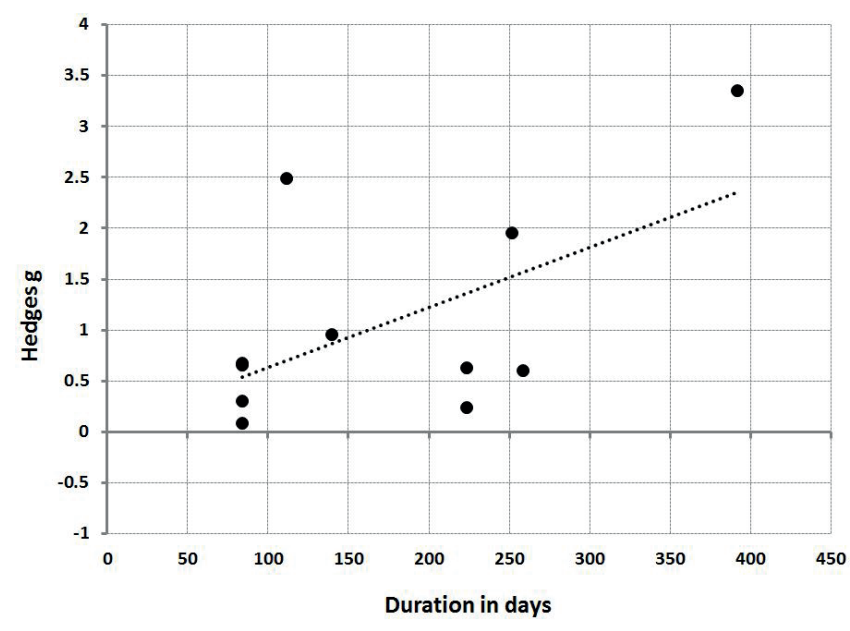

Figure 3. The relationship between training duration and the effect size observed in the case of TDI.

higher in studies among people without olfactory diseases ( $\mathrm{g}$ $=0.64 ; 95 \% \mathrm{Cl}: 0.35-0.93 ; \mathrm{p}<.001$; but this effect was also more heterogeneous: $\mathrm{Q}=8.69 ; \mathrm{df}=3 ; \mathrm{p}=.02$ ) than among patients with olfactory diseases ( $g=0.15 ; 95 \% \mathrm{Cl}:-0.06-0.37 ; \mathrm{p}=.17$ ). The effect obtained in studies among participants without Parkinson's disease $(k=11)$ was small-to-moderate, and statistically significant ( $\mathrm{g}=0.36 ; 95 \% \mathrm{Cl}: 0.12-0.59 ; \mathrm{p}=.004)$, while in a study among participants with Parkinson's disease it was weak and 95\% confidence intervals included 0 ( $g=0.14 ; 95 \% \mathrm{Cl}$ : $-0.64-$ $0.91 ; p=.73)$. These two effects, however, did not differ significantly from one another $(Q=0.28 ; d f=1 ; p=.60)$.

Effects obtained among patients with postinfectious olfactory loss ( $\mathrm{g}=0.32 ; 95 \% \mathrm{Cl}:-0.03-0.67 ; \mathrm{p}=.07$ ) did not differ significantly $(\mathrm{Q}=0.22 ; \mathrm{df}=1 ; \mathrm{p}=.64)$ from effects obtained in the remaining studies ( $g=0.43 ; 95 \% \mathrm{Cl}: 0.12-0.75 ; \mathrm{p}=.007)$. Similarly, we did not observe any statistically significant differences $(\mathrm{Q}=0.79 ; \mathrm{df}=1 ; \mathrm{p}=.37)$ between effects obtained in studies among patients with postinfectious and posttraumatic olfactory loss ( $\mathrm{g}=0.24 ; 95 \% \mathrm{Cl}:-0.07-0.54 ; \mathrm{p}=.13$ ) and the remaining studies ( $g=0.43 ; 95 \% \mathrm{Cl}: 0.12-0.75 ; \mathrm{p}=.007$ ). Effects estimated in studies among older, healthy participants $(\mathrm{g}=0.59 ; 95 \% \mathrm{Cl}$ : $0.10-1.08 ; p=.02)$ did not differ from other studies $(Q=1.26 ; d f$ $=1 ; \mathrm{p}=.26)(\mathrm{g}=0.27 ; 95 \% \mathrm{Cl}: 0.03-0.51 ; \mathrm{p}=.03)$. Training duration was not related to its effectiveness in terms of threshold for odor detection, $\beta=-.18, p=.52$.

\section{TDI score}

An analysis of the potential impact of examined moderators on smell training effectiveness in the case of the total Sniffin' Sticks score (TDI) revealed two statistically significant effects (Table 7). We observed that studies among patients with postinfectious olfactory loss yielded significantly stronger effects than the remaining studies $(\mathrm{Q}=4.34 ; \mathrm{df}=1 ; \mathrm{p}=.04)$, with a strong and significant effect observed among patients ( $g=1.52 ; 95 \% \mathrm{Cl}$ : $0.79-2.25 ; \mathrm{p}<.001)$ and lack of significant effects in the remaining studies ( $g=0.45 ; 95 \% \mathrm{Cl}:-0.25-1.15 ; \mathrm{p}=.21$ ). The same pattern was observed when we collapsed patients with postinfectious and posttraumatic olfactory loss. There was a strong and significant effect among patients ( $\mathrm{g}=1.52 ; 95 \% \mathrm{Cl}$ : 0.79-2.25; $\mathrm{p}$ $<.001)$, while the effect in the remaining studies was non-significant ( $g=0.45 ; 95 \% \mathrm{Cl}:-0.25-1.15 ; p=.21$ ). These effects differed from one another $(Q=6.42 ; d f=1 ; p=.01)$.

On the other hand, when we analyzed studies with all patients with olfactory diseases, the effect was also strong and significant ( $g=1.29 ; 95 \% \mathrm{Cl}: 0.60-1.98 ; \mathrm{p}<.001$ ), but did not differ from the effect obtained in studies conducted among people without olfactory diseases $(\mathrm{Q}=1 ; \mathrm{df}=1 ; \mathrm{p}=.32)(\mathrm{g}=0.63 ; 95 \%$ $\mathrm{Cl}:-0.45-1.72 ; \mathrm{p}=.25)$. Further, the effect obtained in studies among older, healthy participants $(\mathrm{g}=0.63 ; 95 \% \mathrm{Cl}$ : $-0.73-1.98$; $\mathrm{p}=.36)$ did not differ significantly $(\mathrm{Q}=1.26 ; \mathrm{df}=1 ; \mathrm{p}=.26)$ from the effect found in the remaining studies $(\mathrm{g}=1.21 ; 95 \% \mathrm{Cl}: 0.55$ $1.87 ; \mathrm{p}<.001)$. Similar as in the case of identification, training duration was significantly related to its effectiveness, $\beta=.57, p=$ $.02, \mathrm{R} 2=.33$ (Figure 3 ).

\section{Discussion}

In the presented meta-analysis, we analyzed the previous smell training studies to provide a quantitative estimate of the effectiveness of olfactory training across three different olfactory abilities - smell identification, discrimination and threshold for odor detection. Our analyses demonstrate a positive and statistically significant effect of olfactory training in the case of all olfactory abilities, with large effects of training on identification, discrimination and TDI-score ( $g$ between 0.83 and 1.10) and small-to-moderate effect in the case of threshold for odor detection $(g=0.34)$. This overall effectiveness of the olfactory training encouraging, given the importance of olfaction and inconsistent results regarding other forms of olfactory dysfunction treatment. We also aimed to investigate the relationship between the observed olfactory training outcomes, participants' characteristics, and training duration. Interestingly, the pattern of results differed across Sniffin' Sticks subtests depending on the origin of participants' smell disorder, and the smell training duration influenced its effectiveness in the case of identification and the TDI score.

The observed difference between effectiveness of olfactory training for threshold and other evaluated criteria is noteworthy. One source of this difference might be that identification and discrimination are dependent on individuals ' cognitive abilities ${ }^{(31,32)}$, contrary to threshold, which more related to peripheral olfactory system. This seems to be confirmed by the moderator analysis, which revealed a significant difference 
in obtained effects in studies with and without patients with olfactory diseases (all types) in the case of this olfactory ability. The effectiveness of intervention in the case of threshold was higher in studies among people without olfactory diseases, i.e., for healthy older and young individuals and patients with Parkinson's disease. It seems as if peripheral regeneration would happen slower in patients with posttraumatic, postinfectious and idiopathic olfactory loss than in other participants. Thus, our meta-analysis seems to confirm that olfactory training effectiveness depends to a large extent on improved cognitive processing of olfactory information and increased attention paid to odors ${ }^{(9)}$. However, the hypothesis that the repeated exposure to an odorant may modulate regenerative capacity of the olfactory mucosa still deserves further consideration, as the effect of training on threshold was significant.

Concerning the particular groups of participants, our moderator analyses yielded additional noteworthy results. Specifically, our results suggest that the effectiveness of olfactory training appears to vary as a function of the specified patients group and the skill being trained. Characteristics of trainings' participants as well as the duration of the training clearly moderated obtained effects in the case of identification. We observed no significant results of training for Parkinson's disease participants and older people, but the training strongly improved the identification skills of patients suffering from different olfactory diseases (postinfectious, posttraumatic and idiopathic olfactory loss). The analyses showed significant improvement across all olfactory disease subgroups, and therefore we conclude that all patients' subgroups would be likely to benefit from smell training. Importantly, the longer trainings proved to be more effective for identification and (as a result) total TDI score, although there is likely a ceiling effect after a certain, unspecified yet time period. That again opens the question on the optimal time period for the olfactory training ${ }^{(8)}$. It would be also interesting to investigate whether the olfactory function remains constant after the patient finishes the olfactory training. It seems possible, as for example, Konstantinidis et al. ${ }^{(19)}$ observed no decrease in TDI score 40 weeks after the olfactory training. However, more research is necessary before any definite statements can be made. Further, many effects we observed were also heterogeneous, and we found none of the analyzed moderators proved to be significant in the case of discrimination. This warrants future studies on possible moderators.

\section{Conclusion}

Although the exact mechanism of olfactory recovery following the smell training still requires further investigation, our metaanalysis showed that this path is worth exploring. We observed a positive and statistically significant effect of olfactory training in the case of all olfactory abilities, with large effects of training on identification, discrimination and TDI-score and small-tomoderate effect in the case of threshold for odor detection. The neural plasticity of the olfactory system offers possibilities of treatment based on a non-invasive, safe procedure. Olfactory training should thus be considered a simple addition to existing smell treatment methods.

\section{Acknowledgement}

During the project, A.S. was supported by funds from the Polish Ministry of Science and Higher Education (scholarship for the years 2013-2016 and scientific grant luventus Plus \# IP2014 043773 for years 2015-2017), and TH was funded by the Deutsche Forschungsgemeinschaft (DFG HU 411-18/1). The funding sources had no involvement in the study design; in the collection, analysis, and interpretation of the data; in the writing of the report; or in the decision to submit the article for publication.

\section{Authorship contribution}

AS: design, data preparation, write-up of the manuscript.

ED: data preparation, critical discussion and adjustment of manuscript.

MK: design, statistics, write-up of the manuscript.

$\mathrm{TH}$ : design, data collection, critical discussion and adjustent of manuscript.

\section{Conflict of interest}

No conflict of Interest reported.

\section{References}

1. Wilson DA, Best AR, Sullivan RM. Plasticity in the olfactory system: lessons for the neurobiology of memory. Neuroscientist. 2004 Dec;10(6):513-24.

2. Hudson R, Distel H. Induced peripheral sensitivity in the developing vertebrate olfactory system. Ann N Y Acad Sci. 1998 Nov 30:855:109-15.

3. Youngentob SL, Kent PF. Enhancement of odorant-induced mucosal activity patterns in rats trained on an odorant identification task. Brain Res. 1995 Jan 23;670(1):82-8.

4. Wang L, Chen L, Jacob T. Evidence for peripheral plasticity in human odour response. J Physiol. 2004 Jan 1;554(Pt 1):236-44.

5. Altundag A, Cayonu M, Kayabasoglu G, Salihoglu M, Tekeli H, Saglam O, et al. Modified olfactory training in patients with postinfectious olfactory loss. Laryngoscope. 2015 Aug;125(8):1763-6.

6. Damm M, Pikart LK, Reimann H, Burkert $S$, Goktas O, Haxel B, et al. Olfactory training is helpful in postinfectious olfactory loss: a randomized, controlled, multicenter study. Laryngoscope. 2014 Apr;124(4):826-31.

7. Fleiner F, Lau L, Goktas O. Active olfactory training for the treatment of smelling disorders. Ear Nose Throat J. 2012 May;91(5):198203, 15.

8. Geissler K, Reimann H, Gudziol H, Bitter T, Guntinas-Lichius O. Olfactory training for patients with olfactory loss after upper respiratory tract infections. Eur Arch Otorhinolaryngol. 2014 Jun;271(6):1557-62.

9. Haehner A, Tosch C, Wolz M, Klingelhoefer L, Fauser M, Storch A, et al. Olfactory training in patients with Parkinson's disease. PLoS One. 2013;8(4):e61680.

10. Hummel T, Rissom K, Reden J, Hahner A, Weidenbecher M, Huttenbrink KB. Effects of 
olfactory training in patients with olfactory loss. Laryngoscope. 2009 Mar;119(3):496-9.

11. Knudsen K, Flensborg Damholdt M, Mouridsen K, Borghammer P. Olfactory function in Parkinson's Disease - effects of training. Acta Neurol Scand. 2015 Dec;132(6):395-400.

12. Kollndorfer K, Kowalczyk K, Hoche E, Mueller CA, Pollak M, Trattnig S, et al. Recovery of olfactory function induces neuroplasticity effects in patients with smell loss. Neural Plast. 2014:2014:140419.

13. Konstantinidis I, Tsakiropoulou E, Constantinidis J. Long term e ects of olfactory training in patients with postinfectious olfactory loss. Rhinology. 2016 Jun:54(2):170-5.

14. Mori E, Petters W, Schriever VA, Valder C, Hummel T. Exposure to odours improves olfactory function in healthy children. Rhinology. 2015 Sep;53(3):221-6.

15. Murphy C, Schubert CR, Cruickshanks KJ, Klein BE, Klein R, Nondahl DM. Prevalence of olfactory impairment in older adults. JAMA. 2002 Nov 13:288(18):2307-12

16. Negoias S, Aszmann O, Croy I, Hummel T. Localization of odors can be learned. Chem Senses. 2013 Sep;38(7):553-62.

17. Schriever VA, Lehmann S, Prange J, Hummel T. Preventing olfactory deterioration: olfactory training may be of help in older people. J Am Geriatr Soc. 2014 Feb;62(2):384-6.

18. Schubert CR, Cruickshanks KJ, Murphy $C$ Huang GH, Klein BE, Klein R, et al. Olfactory impairment in adults. Ann N Y Acad Sci. 2009 Jul; 1170:531-6.

19. Konstantinidis I, Tsakiropoulou E, Bekiaridou P, Kazantzidou C, Constantinidis J. Use of olfactory training in post-traumatic and postinfectious olfactory dysfunction. Laryngoscope. 2013 Dec;123(12):E85-90.

20. Wegener B-A. Riechtraining mit älteren Menschen. Dresden: TU Dresden; 2015.

21. Tempere S CE, Bougeant JC, de Revel G, Sicard G. Explicit Sensory Training Improves the Olfactory Sensitivity of Wine Experts. Chemosensory Perception. 2012;5(2):20513.

22. Hummel $T$, Sekinger $B$, Wolf SR, Pauli $E_{\text {, }}$
Kobal G. 'Sniffin' sticks': olfactory performance assessed by the combined testing of odor identification, odor discrimination and olfactory threshold. Chem Senses. 1997 Feb;22(1):39-52.

23. Hummel T, Kobal G, Gudziol H, Mackay-Sim A. Normative data for the "Sniffin' Sticks" including tests of odor identification, odor discrimination, and olfactory thresholds: an upgrade based on a group of more than 3,000 subjects. Eur Arch Otorhinolaryngol. 2007 Mar;264(3):237-43.

24. Kobal G, Hummel T, Sekinger B, Barz S, Roscher S, Wolf S. "Sniffin' sticks": screening of olfactory performance. Rhinology. 1996 Dec;34(4):222-6.

25. Cohen J. A power primer. Psychol Bull. 1992 Jul;112(1):155-9.

26. Hedges LV. Estimation of effect size from a series of independent experiments. Psychological Bulletin. 1982;92:490 - 9.

27. Viechtbauer W. Conducting meta-analyses in $\mathrm{R}$ with the metaphor package. Journal of Statistical Software. 2010;36:1-48.

28. Wilson DB. Meta-analysis macros for SAS, SPSS, and Stata. 2014 [updated October, 18, 2014]; Available from: http://mason.gmu. edu/ dwilsonb/ma.html.

29. Duval S, Tweedie R. Trim and fill: A simple funnel-plot-based method of testing and adjusting for publication bias in meta-analysis. Biometrics. 2000 Jun;56(2):455-63.

30. Begg CB, Mazumdar M. Operating characteristics of a rank correlation test for publication bias. Biometrics. 1994 Dec;50(4):1088-101.

31. Hedner M, Larsson M, Arnold N, Zucco GM Hummel T. Cognitive factors in odor detection, odor discrimination, and odor identification tasks. J Clin Exp Neuropsychol. 2010 Dec;32(10):1062-7.

32. Sorokowska A, Sorokowski P, Hummel T, Huanca T. Olfaction and environment: tsimane' of bolivian rainforest have lower threshold of odor detection than industrialized german people. PLoS One. 2013;8(7):e69203.

33. Livermore A, Hummel T. The influence of training on chemosensory event-related potentials and interactions between the olfactory and trigeminal systems. Chem Senses. 2004;29:41-51.

34. Mariño-Sanchez FS, Alobid I, Cantellas S, Alberca C, Guilemany JM, Canals JM, et al. Smell training increases cognitive smell skills of wine tasters compared to the general healthy population. The WINECAT Study. Rhinology. 2010;48:273-6.

35. Tempere S, Cuzange E, Bougeant JC, De Revel G, Sicard G. Explicit sensory training improves the olfactory sensitivity of wine experts. Chemosensory Perception. 2012:5:205-13.

36. Borromeo S, Gomez-Calero C, Molina E, Fernández-Huete J, Martínez-Monge N, Muñoz AT, et al. Objective assessment of a new olfactory rehabilitation approach in adults with olfactory impairments using functional magnetic resonance (fMRI). In: Pons JL, Torricelli D, Pajaro M, editors. Converging Clinical and Engineering Research on Neurorehabilitation. Berlin, Heidelberg.: Springer; 2013. p. 381-4.

37. Negoias S, Aszmann O, Croy I, Hummel T. Localization of Odors Can Be Learned. Chem Senses. 2013 Jun 27;38:553-62.

38. Royet JP, Plailly J, Saive AL, Veyrac A, DelonMartin C. The impact of expertise in olfaction. Front Psychol. 2013;23:928.

Thomas Hummel, M.D.

Smell \& Taste Clinic

Department of Otorhinolaryngology

TU Dresden

Fetscherstrasse 74

01307 Dresden

Germany

Tel: +49-351-458-4189

E-mail:

thummel@mail.zih.tu-dresden.de 